\title{
Biomass fuel use for household cooking in Swaziland: is there an association with anaemia and stunting in children aged 6-36 months?
}

\author{
Mercilene Machisa ${ }^{a}$, Janine Wichmann ${ }^{b}$ and Peter S. Nyasulua,*
}

aDivision of Epidemiology \& Biostatistics, School of Public Health, Faculty of Health Sciences, University of the Witwatersrand, 7 York Road, Parktown 2193, Johannesburg, South Africa; ${ }^{b}$ Environmental and Occupational Health, School of Health Systems and Public Health, University of Pretoria, Pretoria, South Africa

*Corresponding author: Tel: +27 11717 2607; Email: peter.nyasulu@wits.ac.za

Received 20 December 2012; revised 30 May 2013; accepted 30 May 2013

\begin{abstract}
Background: This study is the second to investigate the association between the use of biomass fuels (BMF) for household cooking and anaemia and stunting in children. Such fuels include coal, charcoal, wood, dung and crop residues.
\end{abstract}

\begin{abstract}
Methods: Data from the 2006 - 2007 Swaziland Demographic and Health Survey (a cross-sectional study design) were analysed. Childhood stunting was ascertained through age and height, and anaemia through haemoglobin measurement. The association between BMF use and health outcomes was determined in multinomial logistic regression analyses. Various confounders were considered in the analyses.
\end{abstract}

\begin{abstract}
Results: A total of 1150 children aged 6 - 36 months were included in the statistical analyses, of these 596 (51.8\%) and 317 (27.6\%) were anaemic and stunted, respectively. BMF use was not significantly associated with childhood anaemia in univariate analysis. Independent risk factors for childhood anaemia were child's age, history of diarrhoea and mother's anaemia status. No significant association was observed between BMF use and childhood stunting, after adjusting for child's gender, age, birth weight and preceding birth interval.
\end{abstract}

Conclusion: This study identified the need to prioritize anaemia and stunting as health outcomes and introduction of public health intervention in Swaziland. Further research is needed globally on the potential effects of BMFuse on childhood anaemia and stunting.

Keywords: Anaemia, Biomass fuels, Indoor air pollution, Stunting, Swaziland, Demographic and Health Survey

\section{Introduction}

Half of the world's population still uses polluting fuels such as biomass fuels (BMF, which include coal, charcoal, wood, dung and crop residues) and paraffin (also known as kerosene) in inefficient stoves for cooking and space heating. Combustion of such fuels emits smoke that contains numerous air pollutants, such as $\mathrm{PM}_{10}$ (i.e. particulate matter smaller than $10 \mu \mathrm{m}$ in diameter), $\mathrm{PM}_{2.5}$, soot, nitrogen dioxide, sulphur dioxide and carbon monoxide (CO). ${ }^{1}$

Households that use BMF are often exposed to peak indoor $\mathrm{PM}_{10}$ levels that exceed the air quality guideline of $50 \mu \mathrm{g} / \mathrm{m}^{3}$, according to the WHO. ${ }^{1,2}$ Although the amount of exposure is dependent on the type of fuel used, the nature of the combustion, the location, the length of time individuals spend in the polluted environment and the composition of the smoke, women and children are the most vulnerable. ${ }^{1,3}$ This is because women in developing countries are mainly responsible for cooking and child rearing; mothers carry infants and toddlers on their backs while cooking and expose them for many hours to inhaling polluting fuel smoke. ${ }^{4}$
Children exposed to BMF smoke are more vulnerable than their mothers as they breathe in more air per unit body weight at a given level of respiratory excursion than their mothers. Children exposed to BMF smoke have an increased risk of developing acute lower respiratory tract infections (ALRI) and even die as they do not yet have a fully developed respiratory and immune system. ${ }^{5,6-10}$ Although BMF use has been associated with ALRIs and low birth weight, ${ }^{11,12}$ little is known about its effects on childhood stunting and anaemia. No such study has ever been conducted in Swaziland.

Currently the mechanisms by which BMF use may contribute to anaemia and stunting are uncertain. BMF emits high CO levels, which bind with haemoglobin (required for transporting oxygen to body tissues), form carboxyhaemoglobin and reduce the level of haemoglobin in the blood, which leads to anaemia. CO levels in homes using BMF are occasionally high enough to result in carboxyhaemoglobin levels similar to those in tobacco smokers., ${ }^{4,13}$ BMF smoke exposure can also contribute to stunting by causing not only anaemia but also reduced birth weight, ALRI and other childhood diseases. 
Stunting is reduced height-for-age and is caused by a complex interaction between different social, economic and environmental factors. Tanner concluded that a strong relationship exists between children's height and socioeconomic status (SES) variables. ${ }^{14}$ Apart from poor nutrition, children are vulnerable to other risks such as adverse home environments (e.g. polluting fuels for cooking), which negatively affect their development. ${ }^{14}$ Similarly, anaemia is highly prevalent among children in many low-income countries. ${ }^{15}$ Apart from the role of perinatal factors in contributing to childhood anaemia, previous research indicated that SES factors such as household overcrowding, number of children in the family, education and profession of the parents, source of drinking water, type of sewage system and child's health status are associated with childhood anaemia. ${ }^{16}$

Only one study also investigated the association between BMF household use, anaemia and stunting. Mishra and Retherford did a secondary data analysis of the 1998-1999 National Family Health Survey in India, that included 29768 children aged 0-35 months from 92486 households. ${ }^{17}$ The researchers observed that the prevalence of moderate-to-severe anaemia was significantly higher among children in households using BMF exclusively for cooking and heating than among children in households using cleaner fuels (electricity, liquid petroleum gas, biogas or kerosene) exclusively (relative risk ratio[RRR] $=1.58,95 \%$ CI 1.28-1.94), after adjusting for confounders such as environmental tobacco smoke, child's age and gender, recent episodes of illness, maternal education, maternal nutritional status and household living standard. The prevalence of severe stunting was also significantly higher among children in households that used BMF exclusively for cooking and heating (RRR $=1.84,95 \%$ CI $1.44-2.36)$. Effects of BMF use for cooking and heating on mild anaemia and moderate stunting were smaller, but positive and statistically significant. The study also confirmed a strong positive association between anaemia and stunting in children. $^{17}$

Detailed investigations into environmental factors that promote or suppress linear growth are necessary for a full understanding of the SES-related causes of anaemia and stunting. The current study used data from the 2006 - 2007 Swaziland Demographic Health Survey (SDHS) to investigate the association between BMF use for household cooking and stunting, and anaemia in children aged 6 - 36 months. Approximately $77 \%$ of the population of Swaziland lives in rural areas and $72 \%$ use wood fuel as their primary energy source for cooking and heating. ${ }^{18}$ Wood, coal and charcoal in Swaziland are burnt mostly on open fires or in heavy iron coal stoves that have lower combustion efficiencies. ${ }^{19}$ Despite plans for extensive rural electrification programmes in the country, it is clear that many rural and urban households will not convert to using electricity for cooking due to the unaffordable electricity connections and tariffs. ${ }^{20}$ BMF therefore remain the most important fuel on a gross energy basis in both rural and urban households.

The 2000 Multiple Indicator Cluster Survey showed that $30 \%$ of Swazi children were stunted. ${ }^{21}$ Swaziland is thus an ideal setting to study the relationship between BMF use and stunting because of the overlap in high BMF usage and high prevalence of stunting.

\section{Materials and methods}

\section{Study design and location}

The study had a cross-sectional design and applied secondary data collected in the 2006 - 2007 Swaziland Demographic and Health
Survey (SDHS). ${ }^{18}$ Swaziland is a developing country with a small population of about 1.4 million people and a population growth of $1.2 \%$ per annum. Swaziland ranks as a lower to middle-income country, but it is estimated that $69 \%$ of the population lives in poverty. The infant mortality rate is very high at 63 deaths per every 1000 live births and the current life expectancy is 48.7 years.

\section{Study and target population and sampling}

The 2006 - 2007 SDHS was a nationwide sample survey designed to provide information on various demographic, maternal and child health issues in Swaziland. ${ }^{18}$ Fieldwork was conducted during July 2006 and April 2007.

The SDHS used multistage random sampling. The SDHS sample points (clusters) were selected from a list of enumeration areas (EA) defined in the 1997 Swaziland Population and Housing Census. A total of 275 clusters were drawn from the 1997 census sample frame comprising of 111 in urban areas and 164 in rural areas. The Central Statistics Office staff then conducted an exhaustive listing of households in each of the SDHS clusters and drew a systematic sample of 5500 households.

All women and men (aged 15 - 49years) in the selected households were eligible for individual interviews. In addition, a subsample of half of these households (2750 households) was selected randomly in which all boys and girls aged $12-14$ years (teenagers) and persons aged $\geq 50$ years (elderly) were eligible for individual interviews. In the households where teenagers and the elderly were interviewed, all individuals (aged $\geq 6$ months) were eligible for anaemia testing and all individuals (aged $\geq 2$ years) were eligible for HIV testing.

In the households where only women and men (aged $15-49$ years) were interviewed, children (aged 6 months to 5 years) were eligible for anaemia testing and women and men (aged 15 - 49 years) were eligible for anaemia and HIV testing. The final sample consisted of 4843 households, 4987 women (aged 15 - 49 years), 4156 men (aged 15 - 49 years) and 2812 children (aged $<5$ years); detailed information on the survey design is outlined elsewhere. ${ }^{19}$

Five types of questionnaires were used in the $2006-2007$ SDHS, namely the household, women's, men's, youth and older adult questionnaires. The questionnaires were translated into the local Siswati language. ${ }^{18}$ Data collected with these questionnaires were obtained from the Demographic and Health surveys online archive at http://www.measuredhs.com/data/dataset/Swaziland Standard-DHS_2006. The target population of the current study was children who were aged $6-36$ months at the time of the fieldwork.

\section{Health outcome variables}

The women's questionnaire assessed the health status and risk factors of children. Anthropometric measurements (weight and height) and anaemia testing were recorded in the household questionnaire, as was the information on all the usual members and visitors in the selected households and the consent of eligible household members for the HIV testing. The women's questionnaire assessed other health outcomes and risk factors of children.

The anaemia status of children and their biological mothers were determined with the portable HemoCue system (Kuvettgatan, Angelholm, Sweden). ${ }^{18}$ The system uses a drop of blood from a fingerprick (or heel prick for infants aged $<6$ months), 
which is drawn into a cuvette and then inserted into a portable battery-operated instrument to obtain a digital reading on the haemoglobin concentration. Children were categorized as not anaemic ( $\geq 11.0 \mathrm{~g} / \mathrm{dL})$, mildly anaemic $(10.0-10.9 \mathrm{~g} / \mathrm{dL})$, moderately anaemic $(7.0-9.9 \mathrm{~g} / \mathrm{dL})$ and severely anaemic $(<7.0 \mathrm{~g} / \mathrm{dL}){ }^{19}$ Because the proportion of severely anaemic children was small $(<5 \%)$ in the study population, a three-category response variable for anaemia was used: not anaemic, mildly anaemic and moderately/severely anaemic. ${ }^{22}$

Height measurements were conducted with a measuring board produced by Shorr Productions (Olney, MD, USA). Children aged $<24$ months were measured while lying down (recumbent length) on the board and children aged $\geq 24$ months while standing up. ${ }^{18}$ Children were categorized as mildly stunted if their height-for-age ratio was $2-3$ SDs below the median of the WHO reference population in terms of height-for-age and severely stunted if their heightfor age-ratio was below $<3$ SD from the median of the WHO reference population. ${ }^{23}$

\section{Exposure variable}

The main exposure variable 'BMF use for household cooking' was ascertained in the household questionnaire, 'What fuel does your household mainly use for cooking?', as done in other studies. ${ }^{24}$ The households were grouped into two categories: 'Cleaner fuel use' if liquid petroleum gas/natural gas, electricity and/or paraffin was used exclusively; and 'BMF use' if either coal, charcoal and/or wood were used with or without the cleaner fuels in the fuel combination.

\section{Potential confounders}

The association between BMF use, anaemia and stunting is likely to be confounded by childhood, maternal and household factors (Box 1).

\section{Statistical analysis}

Analyses were performed using STATA 11 (StataCorp. Ltd, College Station, TX, USA). The total number of children (aged $>5$ years) included in the 2006 - 2007 SDHS was $2812 .^{18}$ The following exclusions were made in the statistical analyses: children who were aged $<6$ months and those who were aged $>36$ months; children who did not live with the questionnaire respondent; children who were deceased; children who were visitors at the time of the survey; children from multiple births; and children whose height measurements were missing. In total 1662 children were excluded, leaving a sample size of 1150 children in this investigation.

The associations (RRRs) between the two health outcomes, the main exposure variable and the childhood, maternal and household factors were first assessed in univariate multinomial logistic regression models. Factors that were significantly associated at the 95\% confidence level $(p<0.05)$ with the two health outcomes were included in the multivariate multinomial logistic regression analyses. The estimation of $95 \%$ CIs was used to adjust for clustering at the level of the primary sampling unit.
Box 1. Potential confounders grouped by childhood, maternal and household factors

Childhood factors $^{a}$

- Gender (boy, girl)

- Age (6 - 11, 12 - 23, 24 - 36 months)

- Birth order (1, 2, 3, $\geq 4)$

- Preceding birth interval ( $<24$ months, $\geq 24$ months)

- Birth weight ( $<2500 \mathrm{~g}, \geq 2500 \mathrm{~g}$ )

- Recent episodes of acute lower respiratory tract infection in past 2 weeks (yes/no)

- Recent episodes of fever in past 2 weeks (yes/no)

- Recent episodes of diarrhoea in past 2 weeks (yes/no)

Maternal factors

- Age at the child's birth $(<18,18-24,25-34, \geq 35$ years $)$

- Body mass index at the time of the SDHS $(<18.5,18.5-25.0$, $>25.0 \mathrm{~kg} / \mathrm{m}^{2}$ )

- Highest educational status at the time of the SDHS (no education, primary, secondary, tertiary),

- Iron supplementation during pregnancy (no/yes)

- Anaemia status at the time of the SDHS (mild anaemia: blood haemoglobin level $10.0-10.9 \mathrm{~g} / \mathrm{dL}$ for pregnant women and $10.0-11.9 \mathrm{~g} / \mathrm{dL}$ for non-pregnant women; moderate anaemia: blood haemoglobin level 7.0-9.9 g/dL; severe anaemia: blood haemoglobin level $<7.0 \mathrm{~g} / \mathrm{dL}$ )

Household factors

- Household location at the time of the SDHS (urban/rural),

- Region of household at the time of the SDHS (Hlohlo, Shesweleni, Lubombo, Manzini)

- Crowding at the time of the SDHS ( $<3$ persons/room, $\geq 3$ persons/room)

- Wealth index at the time of the SDHS (low, middle, high) ${ }^{b}$

SDHS: Swaziland Demographic and Health Survey, 2006 - 2007. ${ }^{18}$ 'The child's anaemia status at the time of the SDHS (none, mild, moderate/severe) was also a potential risk factor for stunting. ${ }^{\mathrm{b}}$ The wealth quintiles in the SDHS were used and then grouped into three categories: high, medium and low. ${ }^{18}$

\section{Results}

\section{Description of the study sample}

The sample comprised 1150 children aged $6-36$ months with an almost equal proportion of boys $51.1 \%(n=588)$ and girls $48.9 \%$ $(n=562)$. The majority $76.1 \%(n=875)$ were from rural households and $73.0 \%(n=840)$ came from households whose main cooking fuel was BMF. Overall, 596 (51.8\%) children were anaemic; 271 (23.6\%) were mildly anaemic and 325 (28.3\%) were severely anaemic. Three hundred and seventeen (27.6\%) children were stunted; 194 (16.9\%) were mildly stunted and 123 (10.7\%) were severely stunted (Table 1 ). There was a statistically significant difference in the proportion of rural vs urban households 
M. Machisa et al.

Table 1. Sample distribution of 1150 Swazi children, aged 6 - 36 months, by selected characteristics during July 2006 and April 2007

Characteristic

Child's anaemia status

Normal

Mild

Moderate/severe

Child stunting

Normal

Mild

Severe

Main type of household cooking fuel

Electric

Natural gas

Paraffin

Coal

Charcoal

Wood

Missing data

BMF used for cooking

No

Yes

Missing

Have electricity in household

No

Yes

Missing data

Child's gender

Male

Female

Child's age (months)

$6-11$

$12-23$

$24-36$

Child's birth order

1

2

3

$\geq 4$

Child's birth weight (g)

$<2500$

$\geq 2500$

Child's preceding birth interval (months)

$\leq 24$

$>24$

Child had acute respiratory illness in past 2 weeks

No

Yes

Child had fever in past 2 weeks

No

Yes

Missing

Child had diarrhoea in past 2 weeks

No
Total (\%)

554 (48.2)

271 (23.6)

325 (28.3)

833 (72.4)

194 (16.9)

$123(10.7)$

114 (9.9)

$121(10.5)$

40 (3.5)

$3(0.3)$

$9(0.8)$

828 (72.0)

35 (3.0)

275 (23.9)

$840(73.0)$

35 (3.0)

849 (73.8)

268 (23.3)

33 (2.9)

588 (51.1)

562 (48.9)

$279(24.3)$

$479(41.7)$

392 (34.1)

373 (32.4)

257 (22.3)

168 (14.6)

$352(30.6)$

73 (6.3)

1077 (93.7)

349 (30.3)

801 (69.7)

954 (83.0)

196 (17.0)

$732(63.7)$

$410(35.7)$

$8(0.7)$

897 (78.0)
BMF use $^{\mathrm{a}}$

No BMF use ${ }^{a}$

413

193

234

593

150

97

36

21

114

121

40

0

0

0

-

275

840

740

100

107

168

439

401

131

144

195

350

295

76

113

86

268

172

114

286

87

78

50

60

47

23

793

252

270

570

66

209

684

156

241

34

526

182

309

91

650

216 
Table 1. Continued

\begin{tabular}{|c|c|c|c|}
\hline Characteristic & Total (\%) & BMF use $^{\mathrm{a}}$ & No BMF use ${ }^{a}$ \\
\hline Yes & $253(22.0)$ & 190 & 59 \\
\hline \multicolumn{4}{|c|}{ Mother's age at child's birth (years) } \\
\hline$<25$ & $621(54.0)$ & 469 & 128 \\
\hline$\geq 25$ & $529(46.0)$ & 371 & 147 \\
\hline \multicolumn{4}{|l|}{ Mother's anaemia status } \\
\hline Normal & $883(76.7)$ & 654 & 201 \\
\hline Mild & $209(18.1)$ & 140 & 62 \\
\hline Moderate/severe & $58(5.0)$ & 46 & 12 \\
\hline \multicolumn{4}{|c|}{ Mother's iron supplementation during pregnancy } \\
\hline No & $133(11.6)$ & 101 & 22 \\
\hline Yes & $901(78.4)$ & 650 & 229 \\
\hline Missing data & $116(10.0)$ & - & - \\
\hline \multicolumn{4}{|c|}{ Mother's body mass index $\left(\mathrm{kg} / \mathrm{m}^{2}\right)$} \\
\hline$<18.5$ & $26(2.3)$ & 15 & 10 \\
\hline $18.5-25.0$ & $532(46.3)$ & 404 & 112 \\
\hline$>25.0$ & $592(51.5)$ & 421 & 153 \\
\hline \multicolumn{4}{|c|}{ Mother's highest educational attainment } \\
\hline No education & $96(8.3)$ & 82 & 12 \\
\hline Primary education & $433(37.7)$ & 360 & 57 \\
\hline Secondary education & $559(48.6)$ & 391 & 153 \\
\hline Higher education & $62(5.4)$ & 7 & 53 \\
\hline \multicolumn{4}{|c|}{ Household crowding (people/room) } \\
\hline$<3$ & $490(42.6)$ & 324 & 153 \\
\hline$\geq 3$ & $660(57.4)$ & 516 & 122 \\
\hline \multicolumn{4}{|l|}{ Household wealth index } \\
\hline Middle and lower & $751(65.3)$ & 690 & 44 \\
\hline High & $399(34.7)$ & 150 & 231 \\
\hline \multicolumn{4}{|l|}{ Household's area } \\
\hline Urban & $240(20.9)$ & 57 & 183 \\
\hline Rural & $875(76.1)$ & 783 & 92 \\
\hline Missing & $35(3.0)$ & - & - \\
\hline \multicolumn{4}{|l|}{ Household's region } \\
\hline Hhohho & $274(23.8)$ & 195 & 73 \\
\hline Manzini & $323(28.1)$ & 214 & 102 \\
\hline Shiselwe & $274(23.8)$ & 227 & 38 \\
\hline Lubombo & $279(24.3)$ & 204 & 62 \\
\hline
\end{tabular}

using BMF: $89.5 \%$ (783/875) of rural households used BMF for cooking compared with $23.8 \%$ (57/240) of urban households ( $p<0.001)$. Use of BMF was significantly higher in households of low wealth index (91.9\%; 690/751) compared with middle to high wealth index homes (37.6\%; 150/399) ( $p<0.001)$. There was no statistically significant difference in the proportion of children living in rural or urban areas by age, gender and birth weight.

\section{Univariate analyses}

BMF use for cooking was not associated with anaemia in children. Statistically significant associations were observed between severe anaemia in children and being aged 24-36 months
$(\mathrm{RRR}=0.3,95 \%$ CI $0.2-0.5 ; \mathrm{p}<0.001)$, history of childhood diarrhoea in past 2 weeks (RRR $=2.1,95 \%$ CI 1.5-2.9; $p<0.001$ ), mother's mild anaemia status (RRR $=2.0$, 95\% CI 1.4-2.9; $p<0.001)$ and mother's moderate-to-severe anaemia status $(\mathrm{RRR}=2.4,95 \%$ CI $1.1-5.2 ; p=0.023$ ) (Table 2). Mild anaemia in children was associated with history of childhood diarrhoea in past 2 weeks (RRR $=1.5,95 \%$ CI 1.0-2.3; $p=0.041$ ), mother's mild anaemia status (RRR $=2.0,95 \%$ CI $1.4-3.1 ; p<0.001)$ and mother's moderate-to-severe anaemia status (RRR $=2.3,95 \% \mathrm{CI}$ $1.0-5.3 ; p=0.039)$.

There was a statistically significant difference in the prevalence of mild stunting in children by exposure to BMF use (RRR $=1.6,95 \%$ CI 1.0-2.5; $p=0.037$ ), being aged $12-23$ months (RRR $=2.9,95 \%$ 
Table 2. Crude relative risk ratio (RRR) estimates of household cooking fuel type and other risk factors for stunting and anaemia among 1150 Swazi children (6 - 36 months) during July 2006 and April 2007

Characteristic

BMF used for cooking
No
Yes
Child's anaemia statu
Normal
Mild
Moderate/severe
Child's gender
Male
Female
Child's age (months)
$6-11$
$12-23$
$24-36$
Child's birth order
1
2
3
$\geq 4$

Child's birth weight $(\mathrm{g})$

$<2500$

$\geq 2500$

Child's preceding birth interval (months)

$\leq 24$

$>24$

Child had acute respiratory illness in past 2 weeks

No

Yes

Child had fever in past 2 weeks

No

Yes

Child had diarrhoea in past 2 weeks

No

Yes

Mother's age at child's birth (years)

$<25$

$\geq 25$

Mother's anaemia status

Normal

Mild

Moderate/severe

Mother's iron supplementation during pregnancy

No

Yes

Mother's body mass index $\left(\mathrm{kg} / \mathrm{m}^{2}\right)$

$<18.5$

$18.5-25.0$
Stunting

\begin{tabular}{ll}
\hline Mild & Severe \\
RRR $(95 \%$ CI $)$ & RRR $(95 \%$ CI $)$
\end{tabular}

1

$1.6(1.0-2.5)^{*}$

1

1

$0.9(0.6-1.4)$

$1.1(0.8-1.6)$

1

$0.7(0.5-1.0)$

1

$2.9(1.7-5.1)^{*}$

$3.2(1.8-5.7)^{*}$

1

$1.3(0.9-2.0)$

$0.5(0.3-1.0)$

$1.2(0.8-1.9)$

1

$0.5(0.3-0.9)^{*}$

1

$0.7(0.5-0.9)^{*}$

1

$0.9(0.6-1.4)$

1

$1.0(0.7-1.4)$

1

$1.0(0.7-1.4)$

1

$0.8(0.6-1.1)$

1

$0.9(0.6-1.3)$

$0.9(0.4-1.9)$

1

$0.7(0.4-1.2)$

1

$0.8(0.3-2.3)$
$1.5(0.9-2.6)$

1

$1.4(0.9-2.2)$

$1.4(0.9-2.2)$

1

$0.6(0.4-0.9)^{*}$

1

$2.4(1.4-4.2)^{*}$

$1.6(0.9-2.7)$

1

$0.8(0.5-1.4)$

$0.6(0.3-1.2)$

$1.0(0.6-1.6)$

1

$0.4(0.2-0.7)^{*}$

1

$0.8(0.5-1.3)$

1

$0.7(0.4-1.2)$

1

$1.0(0.7-1.5)$

1

$1.2(0.7-1.8)$

1

$0.6(0.4-1.0)$

1

$1.2(0.7-2.1)$

$1.7(0.8-3.7)$

1

$0.8(0.4-1.5)$

1

$0.5(0.2-1.3)$

Anaemia

\begin{tabular}{ll}
\hline Mild & Moderate/severe \\
RRR $(95 \%$ CI $)$ & RRR $(95 \%$ CI $)$
\end{tabular}

1

$0.8(0.5-1.1)$

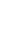

1

$1.0(0.8-1.3)$

1

$1.1(0.8-1.7)$

$0.7(0.5-1.0)$

1

$0.9(0.6-1.4)$

$1.0(0.6-1.6)$

$0.9(0.6-1.4)$

1

$1.1(0.6-2.1)$

1

$1.2(0.8-1.7)$

1

$1.3(0.8-1.9)$

1

$1.3(0.9-1.9)$

1

$1.5(1.0-2.3)^{*}$

1

$0.9(0.7-1.2)$

1

$2.0(1.4-3.1)^{*}$

$2.3(1.0-5.3)^{*}$

1

$1.4(0.9-2.2)$

1

$0.8(0.3-2.2)$
1

$0.8(0.6-1.2)$

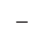

$-$

1

$1.0(0.7-1.3)$

1

$1.3(0.9-1.9)$

$0.3(0.2-0.5)^{*}$

1

$1.0(0.7-1.5)$

$1.0(0.6-1.5)$

$0.9(0.7-1.3)$

1

$0.8(0.5-1.2)$

1

$1.2(0.8-1.6)$

1

$1.4(1.0-2.1)$

1

$1.5(1.1-2.0)$

1

$2.1(1.5-2.9)^{*}$

1

$0.8(0.6-1.1)$

1

$2.0(1.4-2.9)^{*}$

$2.4(1.1-5.2)^{*}$

1

$1.0(0.7-1.6)$

1

$1.1(0.4-3.1)$ 
Table 2. Continued

\begin{tabular}{|c|c|c|c|c|}
\hline \multirow[t]{2}{*}{ Characteristic } & \multicolumn{2}{|l|}{ Stunting } & \multicolumn{2}{|l|}{ Anaemia } \\
\hline & $\begin{array}{l}\text { Mild } \\
\text { RRR (95\% CI) }\end{array}$ & $\begin{array}{l}\text { Severe } \\
\text { RRR (95\% CI) }\end{array}$ & $\begin{array}{l}\text { Mild } \\
\text { RRR }(95 \% \text { CI) }\end{array}$ & $\begin{array}{l}\text { Moderate/severe } \\
\text { RRR }(95 \% \text { CI })\end{array}$ \\
\hline$>25.0$ & $0.7(0.2-2.2)$ & $0.5(0.2-1.5)$ & $0.6(0.2-1.6)$ & $0.7(0.3-2.1)$ \\
\hline \multicolumn{5}{|c|}{ Mother's highest educational attainment } \\
\hline No and primary education & 1 & 1 & 1 & 1 \\
\hline Secondary and higher education & $0.7(0.5-1.0)$ & $0.7(0.5-1.0)$ & $1.1(0.8-1.6)$ & $1.0(0.7-1.3)$ \\
\hline \multicolumn{5}{|l|}{ Household crowding (people/room) } \\
\hline$<3$ & 1 & 1 & 1 & 1 \\
\hline$\geq 3$ & $1.0(0.7-1.4)$ & $1.2(0.8-1.7)$ & $1.2(0.9-1.6)$ & $1.3(1.0-1.7)$ \\
\hline \multicolumn{5}{|l|}{ Household wealth index } \\
\hline Middle and lower & 1 & 1 & 1 & 1 \\
\hline High & $0.7(0.4-0.9)^{*}$ & $0.7(0.5-1.2)$ & $1.0(0.7-1.5)$ & $1.0(0.7-1.3)$ \\
\hline
\end{tabular}

${ }^{*} \mathrm{p}<0.05$.

Models were stratified by household's region.

Table 3. Adjusted relative risk ratio (RRR) estimates of household cooking fuel type and other risk factors for stunting among 1150 Swazi children, aged 6 - 36 months, during July 2006 and April 2007

Characteristic

$\begin{array}{ll}\text { Mild stunting } & \text { Severe } \\ & \text { stunting } \\ \text { RRR (95\% CI) } & \text { RRR }(95 \% \text { CI) }\end{array}$

BMF used for cooking

No

Yes

$1 \quad 1$

Child's gender

Male

Female

$1.1(0.6-2.0) \quad 1.4(0.7-2.7)$

Child's age (months)

$6-11$

$12-23$

$24-36$

Child's birth weight (g)

$$
\begin{aligned}
& <2500 \\
& \geq 2500
\end{aligned}
$$

Child's preceding birth interval (months)

$$
\leq 24
$$$$
>24
$$

$1 \quad 1$

$0.7(0.5-0.9)^{*} \quad 0.6(0.4-0.9)^{*}$

$1 \quad 1$

$3.0(1.7-5.3)^{*} \quad 2.5(1.4-4.5)^{*}$

$3.1(1.7-5.6)^{*} \quad 1.7(1.0-2.9)$

$\begin{array}{ll}1 & 1 \\ 0.3(0.2-0.6)^{*} & 0.3(0.2-0.6)^{*}\end{array}$

Household wealth index

Middle and lower

High

$\begin{array}{ll}1 & 1 \\ 0.7(0.5-1.0)^{*} & 0.7(0.5-1.2) \\ 1 & 1 \\ 0.6(0.4-1.1) & 0.9(0.5-1.5)\end{array}$

${ }^{*} \mathrm{p}<0.05$

Models were stratified by household's region.
CI 1.7-5.1; $p<0.001$ ), being aged $24-36$ months ( $R R R=3.2,95 \% C I$ $1.8-5.7 ; p<0.001$ ), child's normal birth weight (RRR $=0.5,95 \% \mathrm{CI}$ $0.3-0,9 ; p=0.021$ ), preceding birth interval $<24$ months (RRR $=$ $0.7,95 \%$ CI $0.5-0.9 ; p=0.014)$ and higher household wealth index (RRR $=0.7,95 \% \mathrm{CI} 0.4-0.9 ; p=0.026)$. There was a statistically significant difference in the prevalence of severe stunting in children by child gender (RRR $=0.6,95 \% \mathrm{CI} 0.4-0.9 ; p=0.007$ ), child being aged $12-23$ months (RRR $=2.4,95 \%$ CI $1.4-4.2 ; p=0.002$ ) and child's birth weight (RRR $=0.4,95 \%$ CI $0.2-0.7 ; p=0.002$ ) (Table 1).

\section{Multivariate analyses}

The association between BMFuse for household cooking and stunting was weaker and not statistically significant after adjusting for potential confounders. Only female gender (RRR $=0.7,95 \% \mathrm{CI}$ $0.5-0.9 ; p=0.021$ ), child being aged $12-23$ months (RRR $=3.0$, $95 \%$ CI $1.7-5.3 ; p<0.001$ ), child being aged $24-36$ months $(R R R=3.1,95 \%$ CI 1.7-5.6; $p<0.001)$, birth weight $(R R R=0.3$, $95 \%$ CI $0.2-0.6 ; p=0.001)$, and preceding birth interval $>24$ months (RRR $=0.7,95 \%$ CI $0.5-1.0 ; p=0.026$ ) were significantly associated with mild stunting. Female gender (RRR $=0.6,95 \% \mathrm{CI}$ $0.4-0.9 ; p=0.013$ ), child being aged $12-23$ months (RRR $=2.5$, $95 \%$ CI $1.4-4.5 ; p=0.002)$ and birth weight (RRR $=0.3,95 \% C I$ $0.2-0.6 ; p=0.001)$ were significantly associated with severe stunting. Girls were less likely to be stunted compared with boys. Children aged $>12$ months were more likely to be stunted when compared with the youngest age group. Children with normal birth weight were less likely to be stunted compared with those with a low birth weight. Children born more than 2 years apart were less likely to be stunted (Table 3).

\section{Discussion}

The study confirms a high prevalence of BMFuse for cooking among households and a high prevalence of anaemia and stunting in 
children aged 6 - 36 months in Swaziland. An association between BMF use and childhood stunting was observed in univariate analysis. Even though the findings were not significant in multivariate analysis, they were similar to findings of other studies done in other low-income countries. ${ }^{12,25,26}$

In this study, one of the independent risk factors for childhood anaemia was the mother's anaemia status. A dose-response relationship between mother's and child's anaemia status was observed, with the highest risk of anaemia in children among mothers with moderate-to-severe anaemia. These findings are consistent with previous reports ${ }^{27,28}$ suggesting that interventions to prevent anaemia in children aged $<3$ years should include the prevention of anaemia during pregnancy.

Another independent risk factor for childhood anaemia was history of diarrhoea in the past 2 weeks. This could be as a result of poor absorption of micronutrients due to inflammation of the bowels or the presence of intestinal helminths. ${ }^{29,30}$ In addition, acute diarrhoea in children under five could be precipitated by an episode of malarial parasitaemia, a common cause of childhood anaemia in developing countries. ${ }^{31}$

Contrary to the Mishra and Retherford study, ${ }^{17}$ our study showed that girls had a significantly lower risk of stunting compared with boys. This is consistent with other studies conducted in sub-Saharan Africa and Asia. ${ }^{32,33}$ Based on these findings it is worthwhile investigating gender-related differences in childcare or feeding patterns in Swaziland. Children aged $>12$ months were more at risk of stunting and anaemia compared with the youngest age group. The reason could be that the younger age group is probably still being breastfed hence their nutritional status may not have been compromised. These findings are consistent with cross-sectional studies from other developing countries. $^{33-35}$

Findings of a 3-year longitudinal survey conducted in Cameroon reported an age-related decrease in the prevalence of anaemia in children aged $6-60$ months. ${ }^{36}$ Other studies from Pakistan, ${ }^{3}$, Kenya ${ }^{38}$ and Ethiopia ${ }^{39,40}$ and reported similar findings. Our observations provide further evidence in support of public health interventions to reduce stunting and anaemia in children aged $<3$ years. In addition to the above, children born with normal birth weight were less likely to have stunted growth compared with those born with low birth weight, which is biologically plausible and consistent with other research findings. ${ }^{41-43}$

\section{Limitations}

There are some important limitations that need to be taken into account when interpreting the results of this study. The SDHS had a cross-sectional design and an inherent limitation of this epidemiological study design type is the inability to prove causation, since health status and determinants are measured simultaneously. Reliance on self-reported data does include a risk of misclassification of disease and exposure status resulting in statistical significance arising by chance. Information on the confounding factors is based on mothers' reports and there is possibility of recall bias. Exposure to BMF smoke was ascertained indirectly from type of fuel used for household cooking and there is a possibility of non-differential exposure misclassification, which may have underestimated the association between BMF use and the health outcomes.
BMF is also used for heating purposes during colder months, a common practice in developing countries such as Swaziland. The combustion of BMF for heating is done over a longer time period than for cooking. This additional use of BMF was not ascertained in the SHDS. In future SDHS it is imperative to include a question on the type of fuels used for space heating purposes.

There are other factors that may contribute to childhood anaemia and stunting that were not recorded in the SDHS, e.g. outdoor and other indoor air pollution sources (i.e. mothers smoking status, location of household in close proximity to industries, transport services, insecticide or fertiliser use, waste fill sites, dust), access to medical services, mother's pre-pregnancy weight, poor nutritional status, and intestinal helminth, malaria and HIV infection. These are important risk factors and excluding them from the analysis may have led to an underestimation of the observed effects (differential or non-differential misclassification). Not every household member that participated in the survey was tested for HIV, hence we could not adjust for this important confounder.

Nevertheless, this is the first study to investigate the association between BMFuse, anaemia and stunting in children in Sub-Saharan Africa. In addition, the main health outcomes of this the study (anaemia and stunting) were measured directly. In epidemiological studies, the generalizability of data is determined by the response rate. The response rate of the SDHS was $>90 \%$ for both the household and woman's health surveys hence minimal likelihood that bias in this study could be due to non-response.

\section{Conclusion}

The study observed a high prevalence of anaemic and stunted children in the Swazi population. Further research, e.g. use of prospective epidemiological design, on the relationship between indoor BMF smoke exposure and anaemia and stunting is advisable. Programmes or interventions aimed at reducing childhood stunting and anaemia should specifically target boys and other children aged $<3$ years. In addition, other interventions should focus on reducing incidence of diarrhoea, low birth weight and anaemia in pregnant women.

Authors' contributions: JW conceived the study; MM designed the study, analysed and interpreted data, and drafted the manuscript; JW and PSN critically reviewed the manuscript for intellectual content and structured writing. All authors read and approved the final version of manuscript. PSN is guarantor of the paper.

Acknowledgements: The authors thank Dr Annette Gerritsen for her input in editing the manuscript and the Swaziland Statistics office for supplying the data freely through the Demographic and Health surveys on-line archive (http://www.measuredhs.com).

\section{Funding: None}

Competing interests: None declared.

Ethical approval: The study was approved by the University of the Witwatersrand Human Research Ethics Committee, Johannesburg. 


\section{References}

$1 \mathrm{WHO}$. Air quality guidelines for particulate matter, ozone, nitrogen dioxide and sulfur dioxide. Global update 2005. Summary of risk assessment. Geneva: World Health Organization; 2006, WHO/SDE/ PHE/OEH/06.02. http://whqlibdoc.who.int/hq/2006/WHO_SDE_PHE_OEH_ 06.02 eng.pdf [accessed 15 March 2013].

2 Smith KR. Indoor air pollution in developing countries: recommendations for research. Indoor Air 2002;12:198-207.

3 Desai MA, Mehta S, Smith KR. Indoor smoke from solid fuels. Assessing the environmental burden of disease at national and local levels. Geneva: World Health Organization, Protection of the Human Environment; 2004, WHO Environmental Burden of Disease Series No. 4. http://www.who.int/ quantifying_ehimpacts/publications/en/Indoorsmoke.pdf [accessed 15 March 2013].

4 Behera D, Dash S, Malik S. Blood carboxyhaemoglobin levels following acute exposure to smoke of biomass fuel. Indian J Med Res 1988; 88:522-4.

5 Bruce N, Perez-Padilla R, Albalak R. Indoor air pollution in developing countries: a major environmental and public health challenge. Bull World Health Organ 2000;78:1078-92.

6 Kleinman MT. South Coast Air Quality Management District. The health effects of air pollution on children. Irvine, CA: University of California; 2000. http://www.aqmd.gov/forstudents/health_effects_on_children. pdf [accessed 15 March 2013].

7 Ezzati M, Kammen D. Indoor air pollution from biomass combustion and acute respiratory infections in Kenya: an exposure-response study. Lancet 2001;358:619-24.

8 Torres-Duque C, Maldonado D, Pérez-Padilla R et al. Biomass fuels and respiratory diseases: a review of the evidence. Proc Am Thorac Soc 2008;5:577-90.

9 Wichmann J, Voyi KV. Influence of cooking and heating fuel use on 1-59 month old mortality in South Africa. Matern Child Health J 2006;10:553-61.

10 Smith KR, Mehta S, Maeusezahl-Feuz M. Indoor air pollution from household use of solid fuels: comparative quantification of health risks. In: Ezzati MLA, Rodgers A, Murray CJL (editors). Global and Regional Burden of Disease Attributable to Selected Major Risks. Geneva: World Health Organization; 2004, pp.1435-93.

11 Shrestha IL, Shrestha SL. Indoor air pollution from biomass fuels and respiratory health of the exposed population in Nepalese households. Int J Occup Environ Health 2005;11:150-60.

12 Mishra V, Dai X, Smith KR, Mika L. Maternal exposure to biomass smoke and reduced birth weight in Zimbabwe. Ann Epidemiol 2004;14:740 - 7 .

13 Dary O, Pineda O, Belizán JM. Carbon monoxide contamination in dwellings in poor rural areas of Guatemala. Bull Environ Contam Toxicol 1981;26:24-30.

14 Tanner JM. Growth as a mirror of the condition of society: secular trends and class distinctions. In: Demirjian A (editor). Human Growth-A Multidisciplinary Review. London-Philadelphia: Taylor and Francis; 1986, pp.3-34.

15 Zetterström R. Iron deficiency and iron deficiency anaemia during infancy and childhood. Acta Paediatr 2004;93:436-9.

16 Tympa-Psirropoulou E, Vagenas C, Dafni O et al. Environmental risk factors for iron deficiency anaemia in children 12-24 months old in the area of Thessalia in Greece. Hippokratia 2008;12:240 - 50.

17 Mishra V, Retherford RD. Does biofuel smoke contribute to anaemia and stunting in early childhood? Int J Epidemiol 2007;36:117-29.

18 Central Statistical Office (CSO) [Swaziland] and Macro International Inc. 2008. Swaziland Demographic and Health Survey 2006-07. Mbabane, Swaziland: Central Statistical Office and Macro International Inc. http://
www.measuredhs.com/pubs/pdf/FR202/FR202.pdf [accessed 15 March 2013].

19 UNDP/ESMAP. Swaziland Household Energy Strategy Study. Washington DC: Joint United Nations Development Programme/World Bank, Energy Sector Management Assistance Programme; 1997, Report No. 198/97. http://www.esmap.org/sites/esmap.org/files/FR198-97_Swaziland Household_Energy_Strategy_Study.pdf [accessed 15 March 2013].

20 Remmelzwaal A. Swaziland Country Environment Profile (Draft Report). Commission of the European Communities; 2006. http://www.eeas. europa.eu/delegations/swaziland/documents/eu_swaziland/swaziland_ country_environment_profile_june_2006.pdf [accessed 13 March 2013].

21 Swaziland Government. Multiple Indicator Cluster Survey Model Full Report. Mbabane: Central Statistical Office; 2000. http://www. childinfo.org/files/swaziland.pdf [accessed 15 March 2013].

$22 \mathrm{WHO}$. Haemoglobin concentrations for the diagnosis of anaemia and assessment of severity. VMNIS: Vitamin and Mineral Nutrition Information System. Geneva: World Health Organization; 2011, WHO/NMH/ NHD/MNM/11.1. http://www.who.int/vmnis/indicators/haemoglobin. pdf [accessed 16 October 2011].

23 WHO. Multicentre Growth Reference Study Group. Child Growth Standards based on length/height, weight and age. Acta Paediatr 2006;Suppl 450:76-85.

24 Mishra V, Retherford RD. Cooking smoke increases the risk of acute respiratory infection in children. Natl Fam Health Surv Bull 1997; 8:No. 8.

25 Boy E, Bruce N, Delgado H. Birth weight and exposure to kitchen wood smoke during pregnancy in rural Guatemala. Environ Health Perspect 2002;110:109-14.

26 Neufeld LM, Haas JD, Ruel MT et al. Smoky indoor cooking fires are associated with elevated hemoglobin concentration in iron-deficient women. Rev Panam Salud Publica 2004;15:110-8.

27 Samet JM, Tielsch J. Commentary: Could biomass fuel smoke cause anaemia and stunting in early childhood? Int J Epidemiol 2007; $36: 130-1$.

28 Osazuwa F, Ayo OM, Imade P. A significant association between intestinal helminth infection and anaemia burden in children in rural communities of Edo state, Nigeria. N Am J Med Sci 2011;3:30-4.

29 Molyneux ME, Looareesuwan S, Menzies IS et al. Reduced hepatic blood flow and intestinal malabsorption in severe falciparum malaria. Am J Trop Med Hyg 1989;40:470-6.

30 Wilairatana $P$, Meddings JB, Ho $M$ et al. Increased gastrointestinal permeability in patients with Plasmodium falciparum malaria. Clin Infect Dis 1997;24:430-5.

31 Prasad NR, Virk KJ. Malaria as a cause of diarrhoea - a review. PN G Med J 1993;36:337-41.

32 Wamani H, Åstrøm AN, Peterson S et al. Boys are more stunted than girls in sub-Saharan Africa: a meta-analysis of 16 demographic and health surveys. BMC Pediatr 2007; 7:17.

33 Malla S, Shrestha SM. Complementary feeding practices and its impact on nutritional status of under two old children in urban areas of the Kathmandu, Nepal. J Nepal Health Res Counc 2004;2:No. 1.

34 Yimer G. Malnutrition among children in southern Ethiopia: levels and risk factors. Ethiop J Health Dev 2000;14:283-92.

35 Kumar D, Goel NK, Mittal PC, Misra P. Influence of infant-feeding practices on nutritional status of under-five children. Indian J Pediatr 2006;73:417-21.

36 Cornet M, Le Hesran JY, Fievet N. Prevalence of and risk factors for anemia in young children in southern Cameroon. Am J Trop Med Hyg 1998;58:606-11. 
37 Khan MMA, Khattak M, Ali S. Malnutrition and associated risk factors in pre-school children (2-5 years) in district Swabi (NWFP)-Pakistan. J Med Sci 2010;10:34-9.

38 Murila FV, Macharia WM, Wafula EM. Iron deficiency anaemia in children of a peri-urban health facility. East Afr Med J 1999; 76:520 - 3 .

39 Adish AA, Esrey SA, Gyorkos TW, Johns T. Risk factors for iron deficiency anaemia in preschool children in northern Ethiopia. Public Health Nutr 1999;2:243- 52 .

40 Teshome B, Kogi-Makau W, Getahun Z, Taye G. Magnitude and determinants of stunting in children under-five years of age in food surplus region of Ethiopia: the case of West Gojam Zone. Ethiop J Health Dev 2009;23:98-106.

41 Ricci JA, Becker S. Risk factors for wasting and stunting among children in Metro Cebu, Philippines. Am J Clin Nutr 1996;63:966-75.

42 Sommerfelt AE, Stewart MK. Children's nutritional status. Calverton MD: Macro International Inc.; 1994, Demographic and Health Surveys, Comparative studies No. 12. http://www.measuredhs.com/pubs/pdf/ CS12/CS12.pdf [accessed 15 March 2013].

43 Mishra V. Indoor air pollution from biomass combustion and acute respiratory illness in preschool age children in Zimbabwe. Int J Epidemiol 2003;32:847-53. 